\title{
Particle size reduction to the nanometer range: a promising approach to improve buccal absorption of poorly water-soluble drugs
}

This article was published in the following Dove Press journal:

International Journal of Nanomedicine

18 June 2011

Number of times this article has been viewed

\section{Shasha Rao \\ Yunmei Song \\ Frank Peddie \\ Allan M Evans}

Sansom Institute for Health Research, Division of Health Sciences,

University of South Australia,

Adelaide, South Australia, Australia

Correspondence: Allan M Evans Sansom Institute for Health Research, Division of Health Sciences, University of South Australia, GPO Box 247I, Adelaide, SA, 5000, Australia

$\mathrm{Tel}+6 \mathrm{I} 883022028$

Fax +6I 883022030

Email allan.evans@unisa.edu.au

\begin{abstract}
Poorly water-soluble drugs, such as phenylephrine, offer challenging problems for buccal drug delivery. In order to overcome these problems, particle size reduction (to the nanometer range) and cyclodextrin complexation were investigated for permeability enhancement. The apparent solubility in water and the buccal permeation of the original phenylephrine coarse powder, a phenylephrine-cyclodextrin complex and phenylephrine nanosuspensions were characterized. The particle size and particle surface properties of phenylephrine nanosuspensions were used to optimize the size reduction process. The optimized phenylephrine nanosuspension was then freeze dried and incorporated into a multi-layered buccal patch, consisting of a small tablet adhered to a mucoadhesive film, yielding a phenylephrine buccal product with good dosage accuracy and improved mucosal permeability. The design of the buccal patch allows for drug incorporation without the need to change the mucoadhesive component, and is potentially suited to a range of poorly water-soluble compounds.
\end{abstract}

Keywords: buccal drug delivery, nanosuspension, solubility, permeation enhancement, mucoadhesion

\section{Introduction}

The buccal mucosa provides a promising route for the delivery of active pharmaceutical ingredients (APIs). By applying a delivery device to the buccal mucosa, an API can be released into the oral cavity for the treatment of a generalized oral condition or absorbed through the buccal mucosa for systemic therapy. ${ }^{1}$ The buccal route offers potential advantages in being convenient and painless, and it avoids the impact of the harsh gastrointestinal environment and hepatic first-pass metabolism. ${ }^{1,2}$ However, the buccal mucosa represents a significant permeation barrier that limits systemic absorption of APIs, and adequate absorption from this site requires the API to have reasonable solubility in both polar and nonpolar solvents. ${ }^{3,4}$ Because an increasing number of APIs are poorly water-soluble molecules, ${ }^{5}$ techniques to increase the rate of dissolution are required to improve drug absorption through buccal mucosa. Phenylephrine, being slightly water soluble and subject to extensive presystemic metabolism in the gut wall and the liver, ${ }^{6,7}$ was investigated as the model drug in this study.

Conventional formulation approaches for water-solubility enhancement include co-grinding with surfactants, ${ }^{8,9}$ formation of solid dispersions, ${ }^{10,11}$ and inclusion complexes with hydrophilic cyclodextrins. ${ }^{12-15}$ In addition to these techniques, particle size reduction to the nanometer range has also been utilized. ${ }^{16-18}$ For instance, the use of a nanosuspension was able to overcome the low/erratic absorption problem associated with poorly water-soluble drugs after peroral, ${ }^{19,20}$ transdermal, ${ }^{21}$ ocular, ${ }^{22}$ 
or pulmonary ${ }^{23}$ administration. The low particle radius and enlarged surface area of nanosuspensions lead to a consequent improved rate of dissolution that can contribute to increased drug absorption. ${ }^{24-27}$ In this study, the potential benefits of two techniques (formation of cyclodextrin complexes and particle size reduction) in improving the buccal transmucosal permeability of phenylephrine were assessed.

To allow the administration of a nanosuspension via the buccal mucosa, appropriate delivery devices to load the nanosuspensions are required. The preparation process of traditional buccal devices often requires dispersion of the API within the polymeric matrix, ${ }^{28,29}$ which may result in a growth in particle size. In order to overcome this problem, a microreservoir based buccal patch was developed. A phenylephrine nanosuspension was incorporated into the buccal patch and evaluated for dosage accuracy and drug permeability to confirm the applicability of the improved buccal patch for delivering poorly water-soluble APIs.

\section{Material and methods Materials}

Phenylephrine was purchased from ABCR Gmbh \& Co. KG (Baden-Württemberg, Germany). Polymers used in the preparation of mucoadhesive films were hydroxypropylmethylcellulose (HPMC) 2910 (Sigma-Aldrich Co, St Louis, MO) and Carbopol 934P (Lubrizol, Wickliffe, OH). Other excipients used in the preparation of buccal patches were cross-linked polyvinylpyrrolidone (PVPP) (Fluka, SigmaAldrich Co, St Louis, MO), sodium starch glycolate (CMS Na) (JRS Pharma Gmbh \& Co KG, Baden-Württemberg, Germany), polyethylene glycol (PEG) 6000 (ACE Chemical Company, South Australia, Australia), and aerosil R974 (Degussa, Victoria, Australia). Microcrystalline cellulose, lactose, sorbitol, and mannitol used in the preparation of microtablets were generous gifts from Mayne Pharma International Pty Ltd (South Australia, Australia). Other materials used in the preparation and evaluation were PEG 300 (Ph Eur Grade, Sigma-Aldrich Chemie Gmbh, Bavaria, Germany), dibutyl sebacate (Aldrich, Sigma-Aldrich Co, St Louis, MO), ethocel standard 20 (Ethyl cellulose) (Dow Chemical Ltd, New South Wales, Australia), and citric acid (Ward Mckenzie Pty Ld, Victoria, Australia). Water was obtained from a Milli-Q purification system (Millipore Australia Pty Ltd, New South Wales, Australia), and all other chemicals were of analytical grade and were used as received.

Pig cheek tissue was obtained from a local abattoir within 1 hour after slaughter and transported to the laboratory in ice-cold Krebs Bicarbonate Ringer (KBR) buffer (115.5 mM
$\mathrm{NaCl}, 4.2 \mathrm{mM} \mathrm{KCl}, 21.9 \mathrm{mM} \mathrm{NaHCO}, 12.2 \mathrm{mM}$ glucose, $4.0 \mathrm{mM}$ HEPES, $1.2 \mathrm{mM} \mathrm{MgSO} \cdot 7 \mathrm{H}_{2} \mathrm{O}, 2.5 \mathrm{mM} \mathrm{CaCl}_{2} \cdot 2 \mathrm{H}_{2} \mathrm{O}$, and $\left.1.6 \mathrm{mM} \mathrm{NaH}_{2} \mathrm{PO}_{4} \cdot 2 \mathrm{H}_{2} \mathrm{O}, \mathrm{pH} 7.4\right)$. The mucosal epithelium was carefully separated from the underlying tissues using forceps and surgical scissors. The isolated mucosal epithelium was mounted between the donor and the receptor compartment of Franz diffusion cells (specially designed, receptor volume: $15 \mathrm{~mL}$, diffusion area: $1.77 \mathrm{~cm}^{2}$ ) filled with KBR buffer, and equilibrated at $37^{\circ} \mathrm{C}$ for 1 hour prior to use.

\section{HPLC analysis of phenylephrine}

Analysis of phenylephrine in diffusion medium was performed after chromatographic separation on a reversed phase C18 column (Phenomenex ${ }^{\circledR}$ Luna $^{\circledR} 5 \mu \mathrm{m} \mathrm{C18}$ (2), $150 \times 4.6 \mathrm{~mm}$, Torrance, CA). The HPLC system comprised a chromatography pump and a UV variable wavelength UV-vis detector set to $260 \mathrm{~nm}$. The mobile phase was methanol-water (50:50\%, v/v) and 1-octane sulfonic acid (1.1\%, w/v), apparent $\mathrm{pH}$ 6.9. The flow rate was $1.0 \mathrm{~mL} /$ minute, the injection volume was $10 \mu \mathrm{L}$, and the retention time of phenylephrine was 5.1 minutes.

\section{Characterizations of original and modified phenylephrine}

\section{Assessment of apparent solubility in water}

The known excess of phenylephrine was added to $10 \mathrm{~mL}$ of Milli-Q water. The sample was rotated at $20 \mathrm{rpm}$ in a thermostatic chamber $\left(37.0 \pm 0.5^{\circ} \mathrm{C}\right)$ for 72 hours and centrifuged at 4,000 rpm for 10 minutes. The supernatant was then filtered through Acrodisc ${ }^{\circledR}$ Syringe Filters (0.45 $\mu$ m Supor $^{\circledR}$ membrane, Paul Co. Ltd., Ann Arbor, MI) and analyzed by HPLC analysis as described above, from which the apparent solubility was determined.

\section{Particle size and zeta potential assessment}

The measurement of particle size, polydispersity index (PDI) and zeta potential was performed using a Malvern Zetasizer Nano ZS (Malvern Instruments, Worcestershire, UK) with manufacturer's software.

\section{Permeability assessment}

Permeability was measured with porcine buccal mucosal epithelium in Franz diffusion cells. A $2 \mathrm{mg}$ dose of phenylephrine, in the form of phenylephrine solution (3.37, $5.05,9.91 \mathrm{mg} / \mathrm{mL}$ ) or modified phenylephrine, was loaded onto the mucosal surface in the donor compartment. Samples $(0.1 \mathrm{~mL})$ were removed from the receptor compartment 
through the sampling arm at fixed intervals over 4 hours and replaced with fresh KBR buffer $(0.1 \mathrm{~mL})$. Samples were filtered through Acrodisc ${ }^{\circledR}$ Syringe Filters $\left(0.45 \mu \mathrm{m}\right.$ Supor ${ }^{\circledR}$ membrane, Paul Co. Ltd., Ann Arbor, MI) and analyzed by HPLC to detect the amount of phenylephrine reaching the receptor compartment, from which cumulative permeation (as percentage of loading dose) was calculated. All experiments were conducted with 6 replicates, and results are given as mean \pm standard deviation (SD). Steady-state flux $\left(J_{s}\right)$ was calculated using Equation 1, where $d Q$ is the amount of phenylephrine moving through the mucosa during time $d t$, and $A$ is the diffusional area $\left(1.77 \mathrm{~cm}^{2}\right)$.

$$
J_{S}=\frac{d Q}{A(d t)}
$$

\section{Preparation of phenylephrine-hydroxypropyl- $\beta$ -} cyclodextrin complex (PE-HPßCD)

An aqueous 10\% (w/v) hydroxypropyl- $\beta$-cyclodextrin (HP $\beta C D)$ solution was prepared. The solid complex was prepared by adding methanolic phenylephrine $(10 \%, \mathrm{w} / \mathrm{v}$, $2 \mathrm{~mL}$ ) drop wise into the HP $\beta C D$ solution $(10 \mathrm{~mL})$. The clear solution was cooled to $-80^{\circ} \mathrm{C}$ within 2 hours and freeze-dried (Lyph $\cdot$ Lock $^{\circledR}$ Systems, Labconco Co., Kansas City, MI) to form phenylephrine-HP $\beta C D$ complex (PE-HP $\beta C D)$.

\section{Preparation of phenylephrine nanosuspension}

A nanosuspension of phenylephrine (NPE1) was prepared by milling in a mannitol aqueous solution $(50 \%$, $\mathrm{w} / \mathrm{v}$ ) using grinding balls (diameter: $1 \mathrm{~mm}$, zirconium oxide) in a micromill (Fritsch ${ }^{\circledR}$, Planetary Micro Mill PULVERISETTE 7 premium Line, Rhineland-Palatinate, Germany) with a batch size of $10 \mathrm{~mL}$. A second nanosuspension (NPE2) was prepared by high-pressure homogenization of NPE1 (Avestin ${ }^{\circledR}$ EmulsiFlex-C50 Homogenizer, BadenWürttemberg, Germany) under a pressure of 500 to 1000 bar for 30 minutes with a batch size of $10 \mathrm{~mL}$. The milling time and the nanosuspension composition were optimized by in vitro evaluations of apparent solubility, particle size, and transmucosal permeability.

\section{Incorporation of nanosuspension into buccal patches}

\section{Formation of dry nanosuspension}

The optimized nanosuspension was prepared, cooled to $-80^{\circ} \mathrm{C}$ within 2 hours, and freeze dried to form phenylephrine dry nanosuspension (DNPE). A known amount of DNPE was dissolved in Milli-Q water, vortexed and centrifuged at 4,000 rpm for 10 minutes. The supernatant was filtered through Acrodisc ${ }^{\circledR}$ Syringe Filters $\left(0.45 \mu \mathrm{m}\right.$ Supor $^{\circledR}$ membrane, Paul Co. Ltd., Ann Arbor, USA) and assessed by HPLC to determine the content of phenylephrine per unit weight of DNPE $(\%, w / w)$.

Preparation of phenylephrine-containing buccal patch The buccal patch, based on a platform technology developed by Rao et al, ${ }^{30}$ consists of a microreservoir, specifically a microtablet, bound to a bi-layered mucoadhesive film (Figure 1). The two components were prepared separately. The final formulation incorporating coarse phenylephrine powders (PMT1) or phenylephrine dry nanosuspension (PMT2) within the microtablet was prepared by direct manual attachment of the medicated microtablet to the mucoadhesive layer with the aid of ethanol as a moistening agent.

Polymer solutions were prepared by dissolving $4.6 \%(\mathrm{w} / \mathrm{v})$ polymers (Carbopol 934P:HPMC 2910 10:1.5) and 1.6\% (v/v) plasticizer (PEG 300) in 60\% ethanol solution under overhead stirring at $600 \mathrm{rpm}$ for 30 minutes. This solution was transferred to glass plates; the thickness of the solution was controlled to $3.5 \mathrm{~mm}$ and the surface of the solution was flattened using a spatula; the solution was then dried in an oven $\left(60^{\circ} \mathrm{C}\right)$ to form the mucoadhesive layer. For the ethylcellulose layer, 5\% (w/w) ethylcellulose ethanol solution containing $0.4 \%(\mathrm{w} / \mathrm{v})$ of dibutyl sebacate was sprayed via a nozzle onto one side of the mucoadhesive layer $\left(2 \mu \mathrm{L} / \mathrm{cm}^{2}\right)$ and allowed to dry. The patch was then cut with a circular punch (diameter: $20 \mathrm{~mm}$ ) and stored in an airtight container until required.

The microtablet was prepared using the direct compression technique. The appropriate amount of drug and excipients (details given in Table 1) were mixed homogenously, passed through a \#60 (US standard) screen and then compressed in a $7 \mathrm{~mm}$ diameter die, using a Korsch XP-1 tablet press (Korsch AG, Berlin, Germany).

\section{Ex vivo drug permeability assessment}

Drug permeability assessments of the phenylephrine patch were assessed using Franz diffusion cells. Each patch was clamped between the donor and the receptor compartment with the support of porcine buccal mucosa (prepared as described above and equilibrated for 1 hour in KBR buffer). The receptor compartment was filled with dissolution

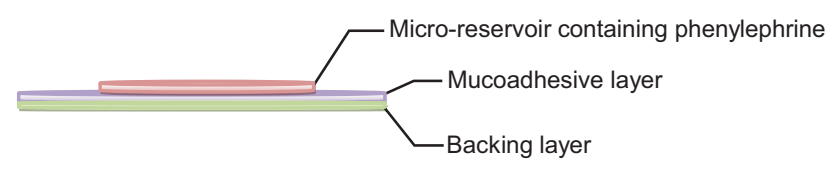

Figure I Phenylephrine-containing buccal patch. 
Table I Compositions of phenylephrine-containing microreservoirs (mg per microtablet)

\begin{tabular}{lllllllll}
\hline Microtablet & Lactose & Mannitol & PVPP & CMS Na & PEG 6000 & Aerosil & Phenylephrine & DNPE \\
\hline PMTI & 11.25 & 15 & 1.875 & 2.625 & 10.5 & 2.25 & 2.5 & $5.0^{\text {a }}$ \\
PMT2 & 11.25 & 12.5 & 1.875 & 2.625 & 10.5 & 2.25 & & \\
\hline
\end{tabular}

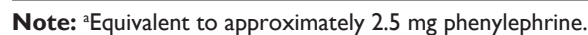

Abbreviations: PEG, polyethylene glycol; PMTI, microtablet-incorporating coarse phenylephrine powders; PMT2, microtablet-incorporating phenylephrine dry nanosuspension; PVPP, polyvinylpyrrolidone; CMS Na, sodium starch glycolate; DNPE, phenylephrine dry nanosuspension.

medium (KBR buffer) and maintained at $37^{\circ} \mathrm{C}$ with constant stirring by a magnetic stirrer. The cumulative amount of drug reaching the receptor at each time point was determined by removing aliquots $(0.1 \mathrm{~mL})$ through the sampling arm at fixed intervals and immediately replacing the same volume of dissolution medium. Samples were filtered through Acrodisc ${ }^{\circledR}$ Syringe Filters with $0.45 \mu \mathrm{m}$ Supor ${ }^{\circledR}$ membrane and analyzed by HPLC. All experiments with either type of buccal mucoadhesive patches were conducted in six replicates, and the results were described as mean $\pm \mathrm{SD}$.

\section{Results}

Incorporating phenylephrine as a hydroxypropyl- $\beta$ cyclodextrin complex (PE-HP $\beta C D$ ) was able to increase its apparent solubility from $10.37 \pm 0.17 \mathrm{mg} / \mathrm{mL}$ for unmodified phenylephrine to $13.82 \pm 0.35 \mathrm{mg} / \mathrm{mL}$ for PE-HP $\beta C D$ complex $(P<0.05)$. Table 2 shows the apparent solubility of a range of phenylephrine nanosuspensions following different size reduction processes. Apparent solubility did not increase constantly as the milling continued, and a 10-minute milling process yielded nanosuspensions with the highest apparent solubility (14.12 mg/mL, NPE1, Table 2). The application of high-pressure homogenization to the milled sample further improved apparent solubility to $17.18 \mathrm{mg} / \mathrm{mL}$ (NPE2, Table 2). Apparent solubility of the final phenylephrine dry nanosuspension (DNPE), obtained after freeze drying NPE2, was $18.31 \mathrm{mg} / \mathrm{mL}$.

Table 2 Preparation process and apparent solubility of nanosuspensions

\begin{tabular}{lll}
\hline & $\begin{array}{l}\text { Media milling } \\
\text { (minutes) }\end{array}$ & $\begin{array}{l}\text { Apparent solubility } \\
\text { after } \mathbf{7 2} \text { hours } \\
(\mathbf{m g} / \mathbf{m L})\end{array}$ \\
\hline NPEI & 0 & 10.37 \\
& 5 & 12.54 \\
& 10 & $14.12^{\mathrm{a}}$ \\
& 15 & 13.91 \\
NPE2 & 20 & 13.44 \\
\hline
\end{tabular}

Notes: aSelected for further studies; ${ }^{b}$ Homogenized for 30 minutes following the milling process.

Abbreviations: NPEI, phenylephrine nanosuspension prepared by milling in a mannitol aqueous solution; NPE2, phenylephrine nanosuspension prepared by high pressure homogenization of NPEI.
Phenylephrine coarse powders were relatively large particles $(>1 \mu \mathrm{m})$ and required milling and high-pressure homogenization processes to form phenylephrine nanosuspensions. Table 3 shows particle size and particle surface properties of the different nanosuspensions. NPE1 presented an average particle size of $832.4 \mathrm{~nm}$, the particle size of NPE2 was $500.3 \mathrm{~nm}$, and DNPE showed a particle size of $216.8 \mathrm{~nm}$ (Table 3). The PDI, a parameter used to measure the width of particle distribution, was below 0.5 for each phenylephrine nanosuspension (Table 3), which indicates the relatively narrow particle size distribution. ${ }^{16}$ The zeta-potential value, which reflects surface properties of nanosized products, was -26.0 , -16.7 and $-15.1 \mathrm{mV}$ for NPE1, NPE2 and DNPE, respectively (Table 3), which fell within the range of $-15 \mathrm{mV}$ to $-30 \mathrm{mV}$ for well-stabilized nanosuspensions. ${ }^{31}$

Using porcine buccal mucosal tissue, a linear relationship was observed between the transmucosal flux and the donor concentration of phenylephrine $\left(R^{2}=0.9999\right.$, Figure 2$)$. Transmucosal flux of phenylephrine solution $(9.911 \mathrm{mg} / \mathrm{mL})$ was $3.27 \pm 0.41 \times 10^{-4} \mathrm{mg} / \mathrm{cm}^{2} \cdot \mathrm{min}$, meaning that for $2.5 \mathrm{mg}$ of phenylephrine to be delivered through an area of approximately $3 \mathrm{~cm}^{2}$, more than 40 hours would be required.

Figure 3 shows that the PE-HP $\beta C D$ complex and the phenylephrine nanosuspensions achieved higher permeability than the unmodified phenylephrine. PE-HP $\beta C D$ and NPE1 had comparable permeability, with more than $0.2 \mathrm{mg}$ of phenylephrine permeating through the mucosa over 240 minutes. Transmucosal flux was $7.78 \pm 0.42 \times 10^{-4}$ $\mathrm{mg} / \mathrm{cm}^{2} \cdot \mathrm{min}$ and $7.32 \pm 0.36 \times 10^{-4} \mathrm{mg} / \mathrm{cm}^{2} \cdot \mathrm{min}$ for PE-HP $\beta C D$ and NPE1, respectively. For NPE2 and DNPE, more pronounced permeation enhancement was

Table 3 Particle size, polydispersity index (PDI) and zeta-potential of coarse powder or nanosuspensions of phenylephrine

\begin{tabular}{llll}
\hline & Particle size $(\mathbf{n m})$ & PDI & Zeta-potential $(\mathbf{m V})$ \\
\hline Coarse & $>1000$ & & \\
NPEI & 832.4 & 0.294 & -26.0 \\
NPE2 & 500.3 & 0.333 & -16.7 \\
DNPE & 216.8 & 0.416 & -15.1 \\
\hline
\end{tabular}

Abbreviations: NPEI, phenylephrine nanosuspension prepared by milling in a mannitol aqueous solution; NPE2, phenylephrine nanosuspension prepared by high pressure homogenization of NPEI; DNPE, phenylephrine dry nanosuspension. 


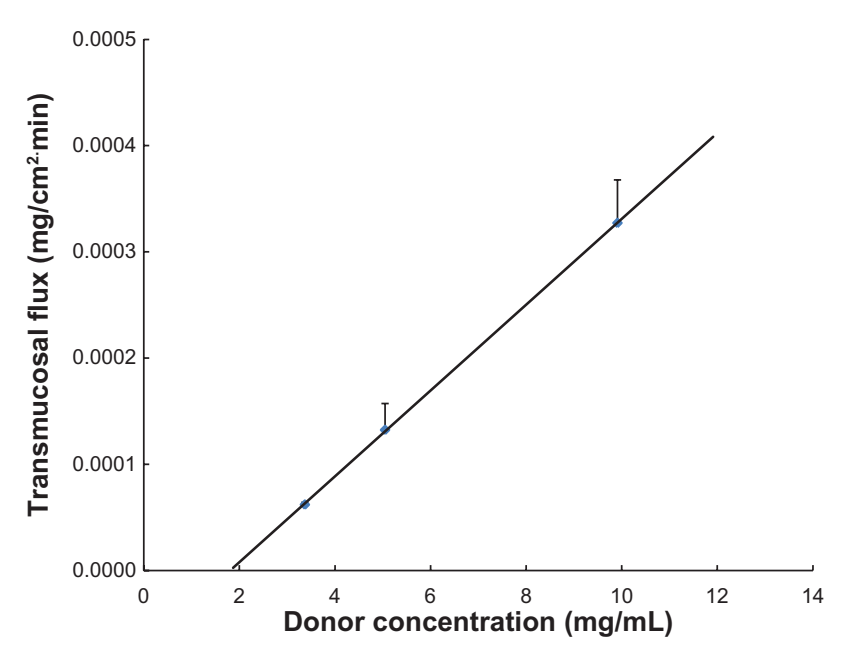

Figure 2 Transmucosal flux of phenylephrine through the porcine buccal mucosa versus the concentration of phenylephrine solution.

achieved, with an approximately 4-fold increase in the transmucosal flux $\left(2.06 \pm 0.36 \times 10^{-3} \mathrm{mg} / \mathrm{cm}^{2} \cdot \mathrm{min}\right.$ for NPE2 and $1.58 \pm 0.22 \times 10^{-3} \mathrm{mg} / \mathrm{cm}^{2} \cdot \min$ for DNPE versus $3.27 \pm 0.41 \times 10^{-4} \mathrm{mg} / \mathrm{cm}^{2} \cdot \mathrm{min}$ for unmodified phenylephrine).
Both PMT1 and PMT2 were found to perform appropriately as potential delivery systems, with acceptable dosage accuracy, containing $2.47 \pm 0.05 \mathrm{mg}$ and $2.42 \pm 0.01 \mathrm{mg}$ of phenylephrine, respectively. The permeability of phenylephrine from the patches varied, with significantly higher drug permeability observed for PMT2 (Figure 4). While a maximum of $5 \%$ of phenylephrine from PMT1 permeated through the mucosa over a period of 180 minutes, this was significantly exceeded by the PMT2 patches. For PMT2, the permeation percentage (as a function of loading dose) was $5.14 \pm 1.01 \%$ at 60 minutes, $9.14 \pm 2.02 \%$ at 120 minutes, and $14.99 \pm 2.39 \%$ at 240 minutes (Figure 4 ).

\section{Discussion}

Buccal drug delivery provides a promising route for the administration of APIs where avoidance of gastrointestinal degradation and hepatic first-pass metabolism is desired. However, efficient systemic drug delivery through buccal mucosa requires suitable water solubility for initial dissolution of the API and adequate transmucosal permeability to ensure movement of the API into the bloodstream. For poorly

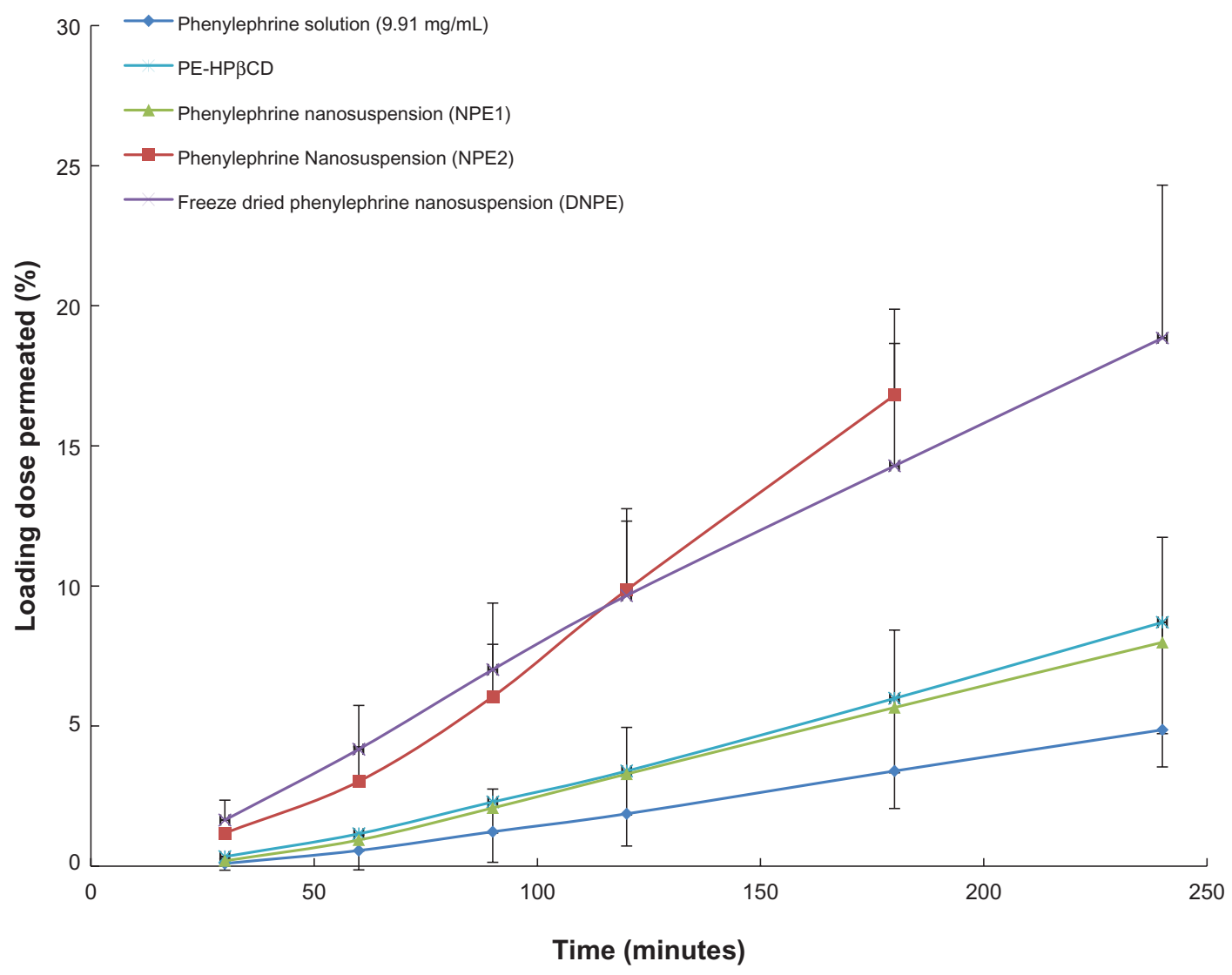

Figure 3 Permeation of phenylephrine through the porcine buccal mucosa, as a function of time. Results are shown for phenylephrine solution (9.9I mg/mL), phenylephrinehydroxypropyl- $\beta$-cyclodextrin complex (PE-HP $\beta C D)$ and phenylephrine nanosuspensions. In all cases, the dose that was applied was 2 mg of phenylephrine.

Abbreviations: NPEI, nanosuspension prepared by milling in a mannitol aqueous solution; NPE2, nanosuspension prepared by high pressure homogenization of NPEI; DNPE, phenylephrine dry nanosuspension. 


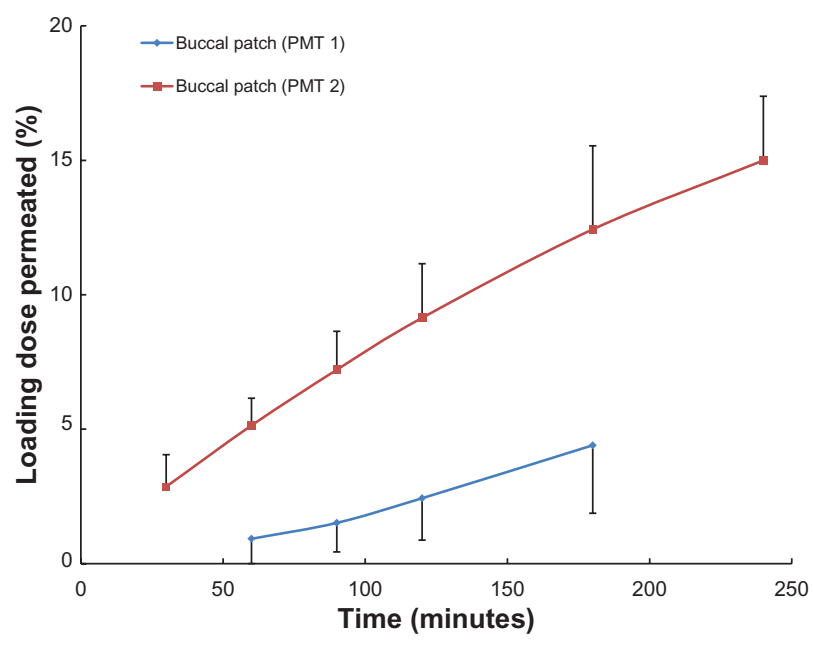

Figure 4 Permeation of phenylephrine through the porcine buccal mucosa, as a function of time. Results are shown for the buccal patch containing coarse phenylephrine powder in the microtablet (PMTI), and the buccal patch containing phenylephrine dry nanosuspension in the microtablet (PMT2).

water-soluble compounds, techniques to increase water solubility or the rate of dissolution are required to increase buccal absorption.

Solubility is generally defined as a compound-specific constant depending only on the temperature and the crystalline structure. However, the rate of dissolution and thus the apparent solubility of phenylephrine were remarkably improved by the formation of a hydroxypropyl- $\beta$-cyclodextrin complex with phenylephrine or the development of a phenylephrine nanosuspension. The increase in apparent solubility then brought a significant increase in transmucosal permeation. A 30\% increase in apparent solubility by cyclodextrin complexation led to a doubling of transmucosal flux through porcine buccal mucosa, and an $80 \%$ increase in apparent solubility via nanosuspension was accompanied by approximately a 4-fold increase in the transmucosal flux. It is postulated that with the increase in apparent solubility, more dissolved drug is presented to the porcine buccal mucosal surface, resulting in a higher concentration gradient across the membrane. Since phenylephrine permeates through buccal mucosa via passive diffusion (confirmed by the linearity between transmucosal flux and donor concentration, Figure 2), the increase in concentration gradient across the membrane contributed to the improved permeability of phenylephrine. Therefore, cyclodextrin inclusion and particle size reduction to the nanometer range were confirmed as two effective techniques to improve buccal transmucosal permeability of phenylephrine via increasing apparent solubility. The feature of mucosal adhesiveness and the consequent prolonged retention at mucosal surface further suggests the use of nanosuspensions for buccal drug delivery may be a promising technique.
Though the development of nanosuspensions may solve the problem of low water solubility and result in enhanced permeation, it is challenging to incorporate nanosuspensions into devices for buccal drug delivery in terms of preserving the nanosize feature. Preparation of traditional buccal devices, typically buccal films, often requires the suspension/ dissolution of drug and polymers in an aqueous media, ${ }^{32,33}$ which will destroy the nanosize feature of nanosuspensions and lead to an increase in particle size. The improved microreservoir-based buccal patch developed in this study consists of a medicated microtablet bound to a mucoadhesive film. The patch enables drug incorporation without direct contact between drug and mucoadhesive polymers, so that drug can be directly released to the mucosal surface without being influenced by the polymeric matrices. This new type of buccal patch has been previously characterized with at least a 2-hour retention time at the human buccal mucosa and with the capability to deliver APIs without potential drug loss into the oral cavity. ${ }^{30}$ Incorporation of phenylephrine dry nanosuspension into the patch yielded products with satisfactory dosage accuracy. In addition, improved drug permeability was achieved with the patch containing phenylephrine nanosuspension, suggesting that the microreservoir based buccal patch may provide a prototype buccal device to deliver poorly water-soluble APIs through buccal mucosa.

\section{Conclusion}

The challenging problems associated with delivering poorly water-soluble APIs through the buccal mucosa can be overcome, at least in part, by water solubility enhancement techniques. Cyclodextrin complexation and size reduction to nanometer range were found to be two techniques able to increase buccal absorption of phenylephrine with more pronounced enhancement achieved with nanosuspensions. Incorporating the phenylephrine nanosuspension into the microreservoir based buccal patch resulted in a satisfactory product, with uniform drug content and relatively high permeability. The microreservoir based buccal patch allowed successful incorporation of nanosuspensions, and could potentially be utilized for the delivery of a range of poorly soluble APIs.

\section{Disclosure}

The authors report no conflicts of interest in this work.

\section{References}

1. Sudhakar Y, Kuotsu K, Bandyopadhyay AK. Buccal bioadhesive drug delivery - a promising option for orally less efficient drugs. J Control Release. 2006;114(1):15-40. 
2. Pather SI, Rathbone MJ, Senel S. Current status and the future of buccal drug delivery systems. Expert Opin Drug Deliv. 2008;5(6): 531-542.

3. Walton RP. Sublingual administration of drugs. J Am Med Assoc. 1944;124(3):138-143.

4. Bickel MH, Weder HJ. Buccal absorption and other properties of pharmacokinetic importance of imipramine and its metabolites. J Pharm Pharmacol. 1969;21(3):160-168.

5. Lipinski C. Poor aqueous solubility - an industry wide problem in drug discovery. Am Pharm Rev. 2002;(5):82-85.

6. Hengstmann JH, Goronzy J. Pharmacokinetics of ${ }^{3} \mathrm{H}$-phenylephrine in man. Eur J Clin Pharmacol. 1982;21(4):335-341.

7. Kanfer I, Dowse R, Vuma V. Pharmacokinetics of oral decongestants. Pharmacotherapy. 1993;13(6 Pt 2):S116-S128; S143-S146.

8. Kile DE, Chiou CT. Water solubility enhancements of DDT and trichlorobenzene by some surfactants below and above the critical micelle concentration. Environ Sci Technol. 1989;23(7):832-838.

9. Balakrishnan A, Rege BD, Amidon GL, Polli JE. Surfactant-mediated dissolution: contributions of solubility enhancement and relatively low micelle diffusivity. J Pharm Sci. 2004;93(8):2064-2075.

10. Betageri GV, Makarla KR. Enhancement of dissolution of glyburide by solid dispersion and lyophilization techniques. Int J Pharm. 1995;126(1-2):155-160.

11. Jung JY, Yoo SD, Lee SH, Kim KH, Yoon DS, Lee KH. Enhanced solubility and dissolution rate of itraconazole by a solid dispersion technique. Int J Pharm. 1999;187(2):209-218.

12. Verhoef JC, Schipper NGM, Romeijn SG, Merkus FWHM. The potential of cyclodextrins as absorption enhancers in nasal delivery of peptide drugs. J Control Release. 1994;29(3):351-360.

13. Jug M, Becirevic Lacan M. Influence of hydroxypropyl-[beta]-cyclodextrin complexation on piroxicam release from buccoadhesive tablets. Eur J Pharm Sci. 2004;21(2-3):251-260.

14. Figueiras A, Carvalho RA, Ribeiro L, Torres Labandeira JJ, Veiga FJB Solid-state characterization and dissolution profiles of the inclusion complexes of omeprazole with native and chemically modified [beta]cyclodextrin. Eur J Pharm Biopharm. 2007;67(2):531-539.

15. Figueiras A, Hombach J, Veiga F, Bernkop Schnürch A. In vitro evaluation of natural and methylated cyclodextrins as buccal permeation enhancing system for omeprazole delivery. Eur J Pharm Biopharm. 2009;71(2):339-345.

16. Müller RH, Jacobs C, Kayser O. Nanosuspensions as particulate drug formulations in therapy: Rationale for development and what we can expect for the future. Adv Drug Deliv Rev. 2001;47(1):3-19.

17. Liversidge GC. Drug nanocrystals for improved drug delivery. The 23rd International Symposium of Controlled Release Bioactive Materials, Workshop on Particulate Drug Delivery Systems, Kyoto, Japan; Jul 7-10, Kyoto, Japan; 1996:74-81.

18. Müller RH. Nanosuspensionen-eine neue formulierung für schwerlösliche arzneistoffe. In: Müller RH, Hildebrand GE, editors. Pharmazeutische Technologie: Moderne Arzneiformen, Lehrbuch für Studierende der Pharmazie-Nachschlagewerk für Apotheker in Offizin, Krankenhaus und Forschung, Stuttgart: Wissenschaftliche; 1998:393-399.
19. Müller RH, Jacobs C. Buparvaquone mucoadhesive nanosuspension: preparation, optimisation and long-term stability. Int J Pharm. 2002;237(1-2):151-161

20. Jacobs C, Kayser O, Müller RH. Production and characterisation of mucoadhesive nanosuspensions for the formulation of bupravaquone. Int J Pharm. 2001;214(1-2):3-7.

21. Mishra PR, Shaal LA, Müller RH, Keck CM. Production and characterization of Hesperetin nanosuspensions for dermal delivery. Int J Pharm. 2009;371(1-2):182-189.

22. Pignatello R, Bucolo C, Ferrara P, Maltese A, Puleo A, Puglisi G. Eudragit RS100 ${ }^{\circledR}$ nanosuspensions for the ophthalmic controlled delivery of ibuprofen. Eur J Pharm Sci. 2002;16(1-2):53-61.

23. Kleemann E, Neu M, Jekel N, et al. Nano-carriers for DNA delivery to the lung based upon a TAT-derived peptide covalently coupled to PEG-PEI. J Control Release. 2005;109(1-3):299-316.

24. Müller RH, Böhm BHL. Nanosuspensions. In: Müller RH, Benita S, Böhm B, editors. Emulsions and Nanosuspensions for the Formulation of Poorly Soluble Drugs, Stuttgart: Medpharm Scientific; 1998: 143-147.

25. Müller RH, Böhm BHL. Nanosuspensions. In: Müller RH, Benita S, Böhm B, editors. Emulsions and Nanosuspensions for the Formulation of Poorly Soluble Drugs, Stuttgart: Medpharm Scientific; 1998: 149-173.

26. Mosharraf M, Nyström C. The effect of particle size and shape on the surface specific dissolution rate of microsized practically insoluble drugs. Int J Pharm. 1995;122(1-2):35-47.

27. Nystrom C. Dissolution properties of soluble drugs: theoretical background and possibilities to improve the dissolution behavior. In: Muller RH, Benita S, Bohm B, editors. Emulsions and Nanosuspensions for the Formulation of Poorly Soluble Drugs, Stuttgart: Medpharm Scientific; 1998:143-147.

28. Nagai T, Machida Y, Konishi R. Bioadhesive dosage forms for buccal/ gingival administration. In: Lenaerts V, Gurny R, editors. Bioadhesive Drug Delivery Systems, Florida: CRC Press, Inc.; 1990:137-152.

29. Guo JH, Cremer K. Development of bioadhesive buccal patches. In: Mathiowitz E, III DEC, Lehr C-M, editors. Bioadhesive Drug Delivery Systems: Fundamentals, Novel Approaches, and Development, New York: Marcel Dekker, Inc.; 1999:541-562.

30. Rao S, Song Y, Peddie F, Evans A. A novel tri-layered buccal mucoadhesive patch for drug delivery: assessment of nicotine delivery. J Pharm Pharmacol. 2011. In press.

31. Kesisoglou F, Panmai S, Wu Y. Nanosizing - oral formulation development and biopharmaceutical evaluation. Adv Drug Deliv Rev. 2007; 59(7):631-644.

32. Diaz del Consuelo I, Falson F, Guy RH, Jacques Y. Ex vivo evaluation of bioadhesive films for buccal delivery of fentanyl. J Control Release. 2007;122(2):135-140.

33. Patel VM, Prajapati BG, Patel JK, Patel MM. Physicochemical characterization and evaluation of buccal adhesive patches containing propranolol hydrochloride. Curr Drug Deliv. 2006;3(3):325-331.
International Journal of Nanomedicine

\section{Publish your work in this journal}

The International Journal of Nanomedicine is an international, peerreviewed journal focusing on the application of nanotechnology in diagnostics, therapeutics, and drug delivery systems throughout the biomedical field. This journal is indexed on PubMed Central,

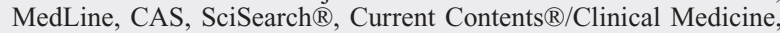

\section{Dovepress}

Journal Citation Reports/Science Edition, EMBase, Scopus and the Elsevier Bibliographic databases. The manuscript management system is completely online and includes a very quick and fair peer-review system, which is all easy to use. Visit http://www.dovepress.com/ testimonials.php to read real quotes from published authors. 